\title{
Insights of health district managers on the implementation of primary health care outreach teams in Johannesburg, South Africa: a descriptive study with focus group discussions
}

\author{
Shabir Moosa', Anselme Derese ${ }^{2}$ and Wim Peersman ${ }^{2,3^{*}}$ (1)
}

\begin{abstract}
Background: Primary health care (PHC) outreach teams are part of a policy of PHC re-engineering in South Africa. It attempts to move the deployment of community health workers (CHWs) from vertical programmes into an integrated generalised team-based approach to care for defined populations in municipal wards. There has little evaluation of PHC outreach teams. Managers' insights are anecdotal.

Methods: This is descriptive qualitative study with focus group discussions with health district managers of Johannesburg, the largest city in South Africa. This was conducted in a sequence of three meetings with questions around implementation, human resources, and integrated PHC teamwork. There was a thematic content analysis of validated transcripts using the framework method.

Results: There were two major themes: leadership-management challenges and human resource challenges. Whilst there was some positive sentiment, leadership-management challenges loomed large: poor leadership and planning with an under-resourced centralised approach, poor communications both within the service and with community, concerns with its impact on current services and resistance to change, and poor integration, both with other streams of PHC re-engineering and current district programmes. Discussion by managers on human resources was mostly on the plight of CHWs and calls for formalisation of CHWs functioning and training and nurse challenges with inappropriate planning and deployment of the team structure, with brief mention of the extended team.

Conclusions: Whilst there is positive sentiment towards intent of the PHC outreach team, programme managers in Johannesburg were critical of management of the programme in their health district. Whilst the objective of PHC reform is people-centred health care, its implementation struggles with a centralising tendency amongst managers in the health service in South Africa. Managers in Johannesburg advocated for decentralisation. The implementation of PHC outreach teams is also limited by difficulties with formalisation and training of CHWs and appropriate task shifting to nurses. Change management is required to create true integrate PHC teamwork. Policy review requires addressing these issues.
\end{abstract}

Keywords: Primary health care, Community healthcare workers, Outreach teams, Africa, Human resources, Policy

\footnotetext{
* Correspondence: Wim.Peersman@UGent.be

${ }^{2}$ Department of Family Medicine and Primary Health Care, Ghent University,

Ghent, Belgium

${ }^{3}$ Knowledge Centre Brussels Integrated Care, Erasmus University College

Brussels, Brussels, Belgium

Full list of author information is available at the end of the article
}

\section{Biomed Central}

(c) The Author(s). 2017 Open Access This article is distributed under the terms of the Creative Commons Attribution 4.0 International License (http://creativecommons.org/licenses/by/4.0/), which permits unrestricted use, distribution, and reproduction in any medium, provided you give appropriate credit to the original author(s) and the source, provide a link to the Creative Commons license, and indicate if changes were made. The Creative Commons Public Domain Dedication waiver (http://creativecommons.org/publicdomain/zero/1.0/) applies to the data made available in this article, unless otherwise stated. 


\section{Background}

There is a growing embrace of community health workers (CHWs) and task shifting to junior professionals as a response to human resource shortages in primary health care. A key difficulty is how to integrate them into health systems to provide comprehensive people-centred primary health care [1-3]. The South African government has been striving to deliver improved public primary health care service for all since 1994, with infrastructural initiatives based on a new district health system. However services remain fragmented, with most doctors and nurses located in the private sector, resulting in poor health outcomes [4]. This is a function of the apartheid past as well as failures in current health leadership-management in South Africa [5].

National Health Insurance (NHI) in South Africa is an attempt to address this public-private inequity, mostly by funding changes $[5,6]$. NHI includes service delivery reform, termed primary health care (PHC) reengineering, as a shift towards more prevention. There are three streams in PHC re-engineering: municipal ward-based PHC outreach teams, school health teams, and district-based clinical specialist teams (to support maternal and child health outcomes mostly) [4, 6]. CHWs have been described by government officials as poorly coordinated, inadequately trained and supervised, randomly distributed in verticalised programmes and struggling with links between the community and fixed clinics [7]. PHC outreach teams are an attempt to change CHWs deployment to a more integrated, teambased approach responsible for defined populations and strengthening interactions between services and service users [8].

The PHC outreach team consists of a professional nurse (a senior nurse trained over three years), supported by a health promoter and environmental health officer, leading a team of six CHWs within the geographic area of a municipal ward, as the unit of election of councillors to local government. Each $\mathrm{CHW}$ takes care of 250 families. The PHC outreach team is supposed to work with another professional nurse and an enrolled nurse (a junior nurse trained over 2 years) at the clinic to provide comprehensive care to this population, from health promotion to treatment of minor ailments [8]. CHWs are to have a standardised scope of work; clearly defined roles, responsibilities and job description; certified training; specified qualification requirements; employment mechanisms; training and supervision packages; and remuneration and condition of service [4]. The CHWs do mostly household profiling, screening, and health education, with supervision by their professional nurse team leader. The CHWs refer problem patients to their supervising professional nurse and/or the clinic nurses and then do community-based follow-up of these patients with health education and home-based care. There may be more than one team per ward, depending on the population.

Johannesburg is one of five health districts/municipal districts in Gauteng Province, which is one of the nine provinces in South Africa. Johannesburg is home to 4.4 million people [9]. Most smaller clinics are managed by local government/municipal managers (known as the City of Johannesburg (CoJ)), whilst the fewer larger community health centres $(\mathrm{CHC})$ are managed by managers appointed by provincial government for the health district (known as Johannesburg Metro). Johannesburg Metro is the principal manager of the health district and CoJ is deemed an agent, in terms of the National Health Act of 2003. Each has a set of programme managers overseeing all verticalised services, e.g. non-communicable diseases or HIV-TB for Johannesburg. There had been various efforts in Johannesburg since 2009 on developing community-oriented primary care (COPC); however, there has been little public examination of the challenges in implementing PHC Outreach Teams, as a stream of $\mathrm{PHC}$ re-engineering.

The aim of this study was to understand the views of district health managers in Johannesburg on the implementation of PHC outreach teams.

\section{Methods}

\section{Study design}

This was a qualitative study, using focus group discussions with managers from both the City of Johannesburg and Johannesburg Metro. Invitations were sent to all senior managers from both local and provincial government in the Johannesburg Health District. These senior managers were at district director, deputy district director and assistant director level and included subdistrict managers, programme managers (including PHC Outreach Team managers), senior doctors and specialists.

\section{Data collection}

Three meetings were organised over a period of 2 months, October to November 2013, where managers responded to particular questions and built on these responses in the subsequent meetings. Written informed consent was obtained from each participant before a 45-60-min focus group discussion was conducted following a standard operating procedure and discussion guide. A total of nine focus group discussions were conducted over the three meetings. Trained researchers facilitated the meetings and discussions. All discussions were conducted in English and digitally recorded.

The first meeting was used to brief all participants on the policy and then addressed the following issue: 
Table 1 Distribution of managers participating at the different focus group discussions

\begin{tabular}{|c|c|c|c|c|}
\hline & Participants & Attended 1 October 2013 & Attended 23 October 2013 & Attended 13 November 2013 \\
\hline Senior managers $(P G)$ & 15 & 11 & 7 & 9 \\
\hline Senior managers (LG) & 5 & 5 & 3 & 3 \\
\hline Junior managers (PG) & 10 & 9 & 2 & 5 \\
\hline Junior managers (LG) & 11 & 8 & 2 & 3 \\
\hline Total attended & 41 & 33 & 14 & 20 \\
\hline
\end{tabular}

PG provincial government

LG local government

1. What are your views on the implementation of the PHC outreach programme across your health district?

In the second meeting, after feedback and reflection from the first meeting, the following question was addressed:

2. What are your views on human resource in implementation of the PHC outreach programme across your health district?

The third meeting reviewed the previous discussions and proceeded to focus on the following two questions:

3. What are your views on integrated PHC teamwork in the implementation of the PHC outreach programme across your health district?

4. What are your views on the challenges of ethics, process and power in the implementation of the PHC outreach programme across your health district?

\section{Data analysis}

The audio recordings were transcribed verbatim. Qualitative data analysis followed the framework method [10]. After the research team had familiarised themselves with the data, and a coding index was agreed upon, all transcripts were systematically coded using NVivo9. The lead researcher (SM) supervised the process. The research team collectively analysed the anonymised coded material in order to develop key findings.

\section{Ethical approval}

The University of the Witwatersrand's Human Research Ethics Committee (Medical) (M130116) gave ethical approval in February 2013. Participants were not offered any monetary reward for participating in the study. The data produced in the project remain confidential, and the participants remain anonymous in all transcripts and analyses. Approval to conduct the study was also given by Gauteng Provincial Department of Health and by the Johannesburg Health District acting Chief Director.

\section{Results}

There were four groups of participants: senior and junior managers from local government (LG) (City of Johannesburg) and provincial government (PG) (Johannesburg Metro). Some senior district managers had deployed junior sub-district managers to represent them (Table 1). There were three meetings (with number of focus groups formed in brackets): 1 October 2013 (4), 23 October 2013 (3) and 13 November 2013 (2).

The results are presented under two main sections: leadership-management challenges and human resource challenges (Table 2). Quotes given by respondents are labelled according to the meeting and focus group number, e.g. 3.2 is focus group two in meeting three.

\section{Leadership and management challenges}

Whilst the programme was seen as positive, this sentiment was overwhelmed by a number of leadership and management challenges: poor leadership and planning, poor communications and consultations, concerns with impact on current services and poor integration.

\section{Positive experiences}

Participants felt that the programme improved access and, more importantly, reduced the burden on clinics. It was reminiscent of older times with community nursing, destroyed due to the post-apartheid focus of nursing on curative care:

It is more a preventative and promotive approach... rather than the curative approach we have in the past

Table 2 Themes and sub-themes

\begin{tabular}{ll}
\hline Themes & Sub-themes \\
\hline $\begin{array}{l}\text { A) Leadership and management } \\
\text { challenges }\end{array}$ & Positive experiences \\
& Poor leadership and planning \\
& Poor communications and \\
consultation \\
Concerns with impact on services \\
Poor integration \\
B) Human resource challenges & Community health workers \\
& Nurses \\
& Extended team \\
\hline
\end{tabular}


... look at the whole ARV (Anti-Retro Viral) programme that is really twisting the way that we use our resource (FGD 1.4)

\section{Poor leadership and planning}

Participants were uncomfortable with different approaches and wanted a standardised approach. Participants ambivalently also felt that this was an opportunity to see what works:

In Jo'burg, there were quite a lot of different views... Everyone has his (own) concept and goes everywhere (FGD 1.2)

If it works well in this clinic let them do it that way (FGD 3.2)

They felt that leadership was poor and uninformed, with limited capacity in the district management responsible for PHC outreach to manage this large project. Participants shared that planning had been poor for years. They thought that the policy needed a clearly phased implementation plan that accounted for communities and contexts:

If you look at the team at district level, it is also very thin. This is a very big district (FGD 1.2)

They did not approve of the current centralised planning and recommended that planning become decentralised and devolved. They said that those on the ground, especially facility managers (as opposed to sub-district managers), could better implement the programme:

Is it a top down approach or (should it not be) a bottom up approach? ... And that is why I am saying, that we need to have a proper plan. (FGD 1.2)

They thought that the programme needed to be adequately resourced with a sustainable budget. There were serious challenges with medical equipment, materials and space for CHWs. This programme was seen as a way to save money in the long term:

You all talk about PHC re-engineering, but where is the financial re-engineering? ... "here is the money for, that is ring-fenced to kick start this sort of process", and slowly merge it into the normal budgetary processes (FGD 1.1)

\section{Poor communications and consultations}

It was also felt that CHWs and staff were not orientated to what each were doing, missing an opportunity for integration and creating an ethical challenge. It was suggested that this influx would decrease over time as prevention and promotion efforts improve. CHWs were seen now as first contact within the health system, doing more than just referring to the clinic, as they appear to be currently doing. They suggested that PHC reengineering required a change to management at a facility level, ensuring that everyone understands this process.

This lack of communication and consultation was not only amongst managers but also between the teams and their communities. Participants intimated that there was poor communication and advocacy around this programme, including with councillors and the community, as people were hearing about the programme in the corridors. There was a clear need for everyone to be properly orientated to the programme:

It was not properly communicated. If I may tell you, I'm confused right now (FGD 1.1)

Managers felt that the programme was not well informed of power relations between councillors, politically linked non-government organisations, clinic committees appointed by provincial government and ward committees appointed by local government:

It's more of political than anything else because you'll find that (the NGO responsible for CHWs) is somebody who's linked to so and so and he has been given a tender (FGD 3.2)

Participants debated whether this programme was invading the privacy of people in their homes and imposing on people's autonomy:

Let's look at the issue of invading people's privacy.... Do we have right to do that? Like health now is imposing on people, people are no longer having decisions to make. (FGD 3.1)

\section{Concerns with impact on current services}

There were major concerns about the influx of patients on an already overburdened service, with high rates of community movement. Clinic staff sees this project as extra work, causing conflict with team leaders. There were concerns about the existing culture of pushing queues:

There is chaos in one of the facilities because people take this as an extra to what they are doing (FGD 2.1)

I've got this mentality of saying: I've done my forty (patients); she must do her forty (patients) (FGD 2.2) 
Participants said that encouraging patients to visit an overworked staff at a clinic offering poor standard care was unethical:

We talk about reengineering, can we reengineer a system that is broken or problematic. Do you see ethical concerns with that maybe? (FGD 3.2)

\section{Poor integration}

The participants shared that this programme is being created as another verticalised, silo programme, with poor integration even between the three streams of PHC Re-engineering. They were also concerned regarding integration with other vertical programmes in the district, with poor briefing of programme managers and social welfare, and the divide between local and provincial government. The programme should belong to everyone in the district with the whole system re-arranged around a common goal:

I want to say that this must not be seen as a separate, different programme altogether. It's part of reengineering primary healthcare (FGD 2.2) This whole model or process is huge ... we are running two parallel services in one area. Local and provincial, and there is nowhere where they come together (FGD 3.1)

\section{Human resource challenges}

Human resources were seen as a serious challenge: community health workers (CHWs), nurses and the extended team:

\section{Community health workers}

Two key CHWs concerns were addressed: formalising the functioning of CHWs and training CHWs. Participants were concerned about the fragmented distribution and unclear roles of CHWs. They felt that CHWs were doing outstanding work and supported generalist CHWs:

We are getting a whole lot of different people and ... duplicating processes ... what they are doing is really outstanding in our community (FGD 1.1)

They were concerned about conditions of CHWs as non-employees: low stipend, non-payment, limited capacity and high burden. They wanted a planned strategy for CHWs, including career progression and professional regulation. They were concerned about security risk, space and logistical support. Participants felt that CHWs need to be selected based on some criteria, more than a matriculation:
Please let's employ them, be part of the staff establishment (FGD 3.1)

Participants were concerned about CHWs training considering their responsibilities:

What is a ten-day course going to do? Nothing (FGD 3.1)

Participants felt that programme managers should be included in a comprehensive and standardised training plan. There was a concern that the reliance on team leaders to provide ongoing training for CHWs was misplaced.

Whilst managers felt that the community viewed $\mathrm{CHWs}$ as professional and favoured CHWs being developed as professionals, they questioned CHWs as professionals, largely with their limited training:

We are sending poorly trained people into communities to do a bad job, that's an ethical problem (FGD 3.2)

There was a tension between the views that CHWs coming from their communities would improve their familiarity and work and the counter view that this closeness made communities uncomfortable about confidentiality. There were concerns about $\mathrm{CHWs}$ safety, identification, debriefing, risk for contracting diseases and professional accountability:

We as professionals, have nursing council, etc. Who covers them (for professional accountability)? (FGD

\section{Nurses}

Managers considered the nursing shortage a serious challenge. It was felt that wards were big and needed more than one team. This could not come from current nursing staff:

At the moment there is such a shortage of staff to implement this, it really becomes a serious challenge (FGD 2.2)

Managers were using school health nurses and district health nurses as team leaders, as they were already working outside the clinic. These nurses were expected to manage this in addition to their current roles, resulting in unhappiness. Clinic staff did not feel responsible for these patients referred from CHWs as they have a team leader. This was especially with a culture of quotas, long tea times and resistance to change: 
I've done my forty patients. If you, yours were difficult one, you are still at number twenty-eight, she was not going to help you. To her, even if it's two o'clock, I'm off; I'm having my long tea. (We need) to break that mentality, that everybody owns everybody else (FGD 2.2)

Managers felt that the team leader should be a dedicated PHC nurse (a professional nurse with postgraduate 18 months training as clinician) so that patients were seen in the community and not referred to other nurse clinicians. Others felt that dedicated clinicians at the clinic could see patients referred by CHWs. It was felt that the clinic itself needed to take responsibility for all patients, especially with nurse shortages. Managers were wary of poorly trained new nurses:

My view is (that the team leader) should be someone who is a clinician (FGD 2.2)

A nurse just out of college shouldn't be taken. They should have some experience (FGD 2.1)

\section{Extended team}

There was also mention of others outside the basic team of nurse team leader and community health worker:

I think there would be a basic team, and their support team and what do you call it, extended team? Not sure. (FGD 3.2)

Whilst doctors were seen as useful to the PHC outreach programme, these managers viewed it as impractical with doctor shortages. The role of the doctor was seen as just providing clinical curative services to those patients referred:

In the ward we could have one doctor for three or four wards, okay (pause) (so) let's not get carried away. (FGD 1.4)

The social worker was felt necessary. Managers mentioned the role of clinical associate, social worker, health promoters, environmental health officers and clinical psychologists.

\section{Discussion}

It is significant that managers in Johannesburg see PHC re-engineering, with its preventive approach and reorientation from specialised to generalist $\mathrm{CHWs}$, as a step in the right direction. It underlines government intent towards a more integrated horizontal approach [7] and its value in PHC [11].

However, managers in Johannesburg quickly pointed out implementation challenges of leadership-management, citing poor planning, poor integration and poor communication. Middle managers suggested that $\mathrm{PHC}$ outreach teams be central to the district's re-arrangement and functioning. They asked the question: 'we talk about reengineering, can we re-engineer a system that is broken?' and questioned the ethics of overwhelming service delivery. Kautzky and Tollman [12] feel that there needs to be an intense effort to salvage the currently over-bureaucratized and rigid primary care service. PHC reform needs a redefinition of strategic and organisational planning of the district health system in South Africa [13]; otherwise, patients will continue to get lost in the system because of lack of integration, as government points out [8]. Conceptualizations of integration appear poor. A salient view is that peoplecentredness should be the organising focus of integrated PHC [14]. However, the tendency is for managers, especially senior district managers, to organise and integrate around themselves and the bureaucratic structures they create.

This was evident with managers cautioning about the impact on current services with the current culture of 'pushing queues'. They thought that clinic staff would see this as extra work and resist changes. Sub-district managers say that facility and operational managers are unable to see the big picture [15]. The shortages of equipment, supplies and transport seemed to reflect a currently dysfunctional service that needed 'financial re-engineering' rather than a lack of resources. South Africa already spends the second highest percentage of government expenditure on health in Africa [16]. These challenges of lack of leadership, integration and service take up in PHC Outreach teams are not unique to Johannesburg [17].

Current command and control approaches are seen as flawed with a bottom-up approach suggested as critical [18]. Managers in Johannesburg recommended that management and planning should be decentralised to facility managers. Decision space is required for managers [19]. A service interface empowered as close to the community is likely to be patient-, person- and people-centred [12]. Decentralisation is an important call in Africa [20, 21] and South Africa [22]. There is a need for a complex adaptive systems thinking approach. There needs to pro-active management, local service improvement priorities and population accountability [23]. Managerialism in the public service can demobilise communities, rendering community participation very patronising [24]. Familiarity with the community by all providers improves community engagement and service integration [25] but also risked the invasion of privacy and confidentiality. Managers shared this sentiment. They were also worried about patient autonomy with the PHC outreach teams. 
Managers considered human resource challenges as a serious challenge, with most of their focus on CHWs. They saw the service profoundly shifting to make the CHWs the first point of contact with the formal health system and addressing the current verticalised programmatic fragmentation of care. This seems aligned with national intent $[8,26]$ and good practice internationally [27-29]. CHWs understand contexts and social situations from which their patients come and manage a myriad of social challenges within families and communities, congruent with international evidence of promising benefits [30].

Managers' in Johannesburg wanted the formalisation of CHWs, especially in respect of incentives. This is an important consideration in a systematic review of design factors influencing performance of CHWs in low- and middle-income countries [1]. Managers felt that the CHW workload was very heavy and their working conditions difficult, citing the lack of space, stationery and equipment. This is not unique to South Africa [31] and influences $\mathrm{CHWs}$ productivity [32]. CHWs deployment requires a strengthening of the existing health system and an enabling environment for CHWs [29, 33]. Managers shared sentiments in line with international calls for better recruitment, standardisation and performance management [33, 34].

Managers felt the need for more formalised CHW training, with the amount of complexity being thrust on CHWs without the ability to cope. This concern is evident in other programmes in Africa [35], with community criticism of $\mathrm{CHWs}$ competence jeopardising the programme [36]. Managers in Johannesburg felt that the training focus should be local and more than just a tenday course.

CHWs are politically powerful being 'agents of the state' being very present in the community and potentially holding the key to access of health services. On the other hand, their employment may render them as bureaucratic extensions of a dysfunctional health service, where their role as advocates for social change is replaced by a predominantly technical community management function [37, 38]. Politicians see CHWs as a panacea to all their problems and there is a danger that the $\mathrm{CHW}$ programme will take on more than it can deliver [26, 29].

Formalising CHWs would require significant budget but costs could be modest [27, 39]. Managers questioned the ethics of holding CHWs in a state of precarity: exposed to risks, poorly supported, poorly and often irregularly paid. This lack of care for the carer is symptomatic of the entire public service [40] and creates the impression that CHWs are readily disposable.

Government has premised the PHC outreach team on professional nurses as team leaders [17]. Participants saw this requirement as unrealistic and suggested using enrolled nurses instead. Managers in Johannesburg questioned the use of school and district nurses and the choice of inexperienced nurses as new team leaders. Managers suggested that teams be linked to a PHC Nurse based at the clinic, seeing referred patients and able to see patients comprehensively. However, such teamwork is confounded by their concern about the culture of quotas and long teas amongst staff. A major reason for dissatisfaction with health services is the non-responsiveness of the nursing profession and the non-caring attitude of health care personnel [18, 41]. Change management, dealing with resistance, appears a key hurdle on which implementation of PHC Re-engineering appears to be stumbling $[42,43]$. Task shifting can be useful but overburdening lowly-paid health workers with very complex tasks can be counterproductive, whatever the short-term cost benefits may appear. Integration with task shifting needs local clinical leadership to manage the staff-skills mix [44]. Task shifting is more than substitution and delegation. It includes supervision, enhancement, mentoring and innovation [45]. Managers in Johannesburg felt that the capacity of facility managers was limited and needed changing. Clinic managers are struggling with the same problems as general staff: poor practice environment, workload, professional support, training, pay, standards of care and security [46]. Whether leadership training is enough to address the current culture is moot. The relegation by managers of doctors to clinical curative work and the poor use of clinical associates is of concern [47-50]

There are limitations to this study. It obtains views of only one health district in Gauteng. Some key members of management are noted as missing. The research team involvement in previous work on $\mathrm{PHC}$ outreach teams may have biased results. Further such research is required in other districts. The study was done in 2013 and may be dated.

\section{Conclusions}

There needs to be a review of the South African policy of $\mathrm{PHC}$ re-engineering, especially related to district management, roles and norms of staffing, formalisation of CHWs and their training, especially as health professionals in line with various proposals [51-53]. Implementation of PHC outreach teams needs to include a true re-engineering of $\mathrm{PHC}$ at a health district level. Implementation should be allied with stronger devolution of power to facility level, together with appropriate resources. Communities should be actively engaged in the process. 


\section{Abbreviations}

CHW: Community health worker; CoJ: City of Johannesburg; NHI: National Health Insurance; PHC: Primary Health Care

\section{Acknowledgements}

Not applicable.

\section{Funding}

This study was undertaken as part of the HURAPRIM Project, which received funding from the European Union's Seventh Framework Programme (FP7AFRICA-2010) under grant agreement no. 265727.

\section{Availability of data and materials}

The data that support the findings of this study are available from the corresponding author upon reasonable request. The data are not publicly available due to containing information that could compromise research participant privacy and consent.

\section{Authors' contributions}

SM conceptualised and initiated the research. WP participated in the design of the study. SM, AD and WP were involved in the analysis, drafting and finalisation of the manuscript. All authors read and approved the final manuscript.

\section{Competing interests}

The authors declare that they have no competing interests.

\section{Consent for publication}

Not applicable.

\section{Ethics approval and consent to participate}

The University of the Witwatersrand's Human Research Ethics Committee (Medical) (M130116) gave ethical approval in February 2013. Written informed consent was obtained from each participant before a 45-60-min focus group discussion was conducted. Approval to conduct the study was also given by Gauteng Provincial Department of Health and by the Johannesburg Health District acting Chief Director.

\section{Author details}

'Department of Family Medicine, University of Witwatersrand, Johannesburg, South Africa. ${ }^{2}$ Department of Family Medicine and Primary Health Care, Ghent University, Ghent, Belgium. ${ }^{3}$ Knowledge Centre Brussels Integrated Care, Erasmus University College Brussels, Brussels, Belgium.

Received: 10 October 2016 Accepted: 12 January 2017

Published online: 21 January 2017

\section{References}

1. Kok MC, Dieleman M, Taegtmeyer M, Broerse JEW, Kane SS, Ormel H, et al. Which intervention design factors influence performance of community health workers in low- and middle-income countries? A systematic review. Health Policy Plan. 2015;30(9):1207-27.

2. Fulton BD, Scheffler RM, Sparkes SP, Auh EY, Vujicic M, Soucat A. Health workforce skill mix and task shifting in low income countries: a review of recent evidence. Hum Resour Health. 2011;9(1):1. BioMed Central Ltd.

3. Braun R, Catalani C, Wimbush J, Israelski D. Community health workers and mobile technology: a systematic review of the literature. PLoS One. 2013; 8(6):4-9.

4. National Department of Health. Human resources for health South Africa: HRH Strategy for the Health Sector: 2012/13 - 2016/17. Pretoria: Department of Health (South Africa); 2011.

5. Coovadia H, Jewkes R, Barron P, Sanders D, McIntyre D. The health and health system of South Africa: historical roots of current public health challenges. Lancet. 2009;374(9692):817-34. Elsevier.

6. National Department of Health. Policy Paper: National Health Insurance in South Africa. Pretoria: Department of Health (South Africa); 2011.

7. Pillay $Y$, Barron P. The implementation of PHC re-engineering in South Africa. In: PHASA Conference. 2011. p. 1-6

8. National Department of Health. Provincial guidelines for the implementation of the three streams of PHC re-engineering. Pretoria: Department of Health (South Africa); 2011.
9. City of Johannesburg. City of Johannesburg: 2012/16 integrated development plan: 2013/14 Review. Johannesburg: City of Johannesburg; 2013.

10. Ritchie JSL. Qualitative data analysis for applied policy research. In: Bryman A, Burgess R, editors. Analysing Qualitative Data. London: Routledge; 1993. p. $173-94$.

11. Lawn J, Rohde J, Rifkin S, Were M, Paul V, Chopra M. Alma-Ata 30 years on: revolutionary, relevant, and time to revitalise. Lancet. 2008;372(9642):972-89.

12. Kautzky K, Tollman S. A perspective on primary health care in South Africa. In: Barron P, Roma-Reardon J, editors. South African Health Review. Durban: Health Systems Trust; 2008. p. 17-30.

13. Dookie S, Singh S. Primary health services at district level in South Africa: a critique of the primary health care approach. BMC Fam Pract. 2012;13(1):67.

14. World Health Organisation. Everybody's business: strengthening health systems to improve health outcomes, WHO's framework for action. Geneva: WHO; 2007

15. Elloker S, Olckers P, Gilson L, Lehmann U. Crises, routines and innovations: the complexities and possibilities of sub-district management. In: Barron P, editor. South African Health Review. 2012/13th ed. Durban: Health Systems Trust; 2012. p. 161-73.

16. World Health Organisation Regional Office for Africa. WHO African Region Expenditure Atlas. Brazzaville: WHO; 2014.

17. Padayachee T, Chetty N, Matse M, Mampe T, Schneider H. Progress in the establishment of ward-based outreach teams: experiences in North West Province. In: Padarath A, English R, editors. South Africa Health Review 2013/14. Durban: Health Systems Trust; 2014.

18. Gilson L, Daire J. Leadership and governance within the South African health system. In: Padarath A, English R, editors. South African Health Review. Pretoria: Health Systems Trust; 2011. p. 69-80.

19. Bossert T. Analyzing the decentralization of health systems in developing countries: decision space, innovation and performance. Soc Sci Med. 1998; 47(10):1513-27.

20. Member States of the African Region of World Health Organisation. The Ouagadougou declaration on primary health care and health systems in Africa: achieving better health for Africa in the new millennium. Brazzaville: WHO; 2008

21. African Union. Africa Health Strategy: 2007-2015. 2007.

22. Pillay Y, Leon N. Guidelines for functional integration. Pretoria: Department of Health (South Africa); 2003.

23. Gilson L, Elloker S, Olckers P, Lehmann U. Advancing the application of systems thinking in health: South African examples of a leadership of sensemaking for primary health care. Heal Res policy Syst. 2014;12(1):30.

24. Heller P. Moving the state: the politics of democratic decentralization in Kerala, South Africa, and Porto Alegre. Polit Soc. 2001;29:131-63.

25. Pinto R, da Silva S, Soriano R. Community health workers in Brazil's unified health system: a framework of their praxis and contributions to patient health behaviors. Soc Sci Med. 2012;74(6):940-7.

26. Clarke M, Dick J, Lewin S. Community health workers in South Africa: where in this maze do we find ourselves? S Afr Med J. 2008;98(9):680-1.

27. Technical Task Force. One million community health workers. 2011.

28. Sprague L. Community health workers: a front line for primary care? Issue Brief Natl Health Policy Forum. 2012;846:1-12.

29. Lehmann U, Sanders D. Community health workers: what do we know about them? Geneva: World Health Organisation; 2007.

30. Lewin S, Babigumira S, Bosch-Capblanch X, Aja G, van Wyk B, Glenton C, et al. REPORT: Lay health workers in primary and community health care: a systematic review of trials. London: London School of Hygiene and Tropical Medicine; 2006.

31. Javanparast S, Baum F, Labonte R, Sanders D. Community health workers' perspectives on their contribution to rural health and well-being in Iran. Am J Public Health. 2011;101(12):2287-92.

32. Jaskiewicz W, Tulenko K. Increasing community health worker productivity and effectiveness: a review of the influence of the work environment. Hum Resour Health. 2012;10(1):38.

33. Global Health Workforce Alliance. Integrating community health workers in national health workforce plans. In: Global Consultation on Community Health Workers. Montreux: Global Health Workforce Alliance; 2010.

34. UNICEF Regional Office of South Asia. What works for children in South Asia: community health workers. Kathmandu: UNICEF; 2004.

35. Medhanyie A, Spigt M, Dinant G, Blanco R. Knowledge and performance of the Ethiopian health extension workers on antenatal and delivery care: a cross-sectional study. Hum Resour Health. 2012;10(1):44. 
36. Birhanu Z, Godesso A, Kebede Y, Gerbaba M. Mothers' experiences and satisfactions with health extension program in Jimma zone, Ethiopia: a cross sectional study. BMC Health Serv Res. BMC Health Serv Res. 2013;13(1):74.

37. Vale E. "You must make a plan or [...] some story": community health workers' re-appropriation of the care manual. Cape Town: Centre for Social Science Research, UCT; 2012.

38. Lehmann U, Friedman I, Sanders D, Africa S. REPORT: review of the utilisation and effectiveness of community-based health workers in Africa. Cape Town: School of Public Health, University of the Western Cape; 2004

39. McCord G, Liu A, Singh P. Deployment of community health workers across rural sub-Saharan Africa: financial considerations and assumptions. Bull World Health Org. 2013;91(4):244-53B.

40. Heywood M. The broken thread: primary health care, social justice and the dignity of the health worker. Johannesburg: WiSER, History Workshop and Wits Political Studies Department; 2014.

41. National Department of Health. Negotiated service delivery agreement for outcome 2: a long and healthy life for all South Africans. Pretoria: Department of Health (South Africa); 2010

42. Nxumalo N, Choonara S. Ward-based community health worker outreach teams: the success of the Sedibeng Health Posts. Policy Brief. Johannesburg: University of Witwatersrand; 2014

43. Bam N, Marcus T, Hugo J, Kinkel H-F. Conceptualizing Community Oriented Primary Care (COPC)—the Tshwane, South Africa, health post model. African J Prim Heal Care Fam Med. 2013;5(1):3.

44. Dubois C-A, Singh D. From staff-mix to skill-mix and beyond: towards a systemic approach to health workforce management. Hum Resour Health 2009;7:87.

45. World Health Organisation. Task shifting to tackle health worker shortages. 2007.

46. Munyewende PO, Rispel LC, Chirwa T. Positive practice environments influence job satisfaction of primary health care clinic nursing managers in two South African provinces. Hum Resour Health. 2014;12(1):27.

47. Cooke R, Couper I, Versteeg M. Human resources for rural health. In: Barron P, editor. South African Health Review. Durban: Health Systems Trust; 2011. p. 107-18.

48. Harzheim E, Duncan BB, Stein AT, Cunha CRH, Goncalves MR, Trindade TG, et al. Quality and effectiveness of different approaches to primary care delivery in Brazil. BMC Health Serv Res. 2006;6:156.

49. von Holdt K. Nationalism, bureaucracy and the developmental state: the South African case. S Afr Rev Sociol. 2010;41:4-27.

50. Moosa S, Gibbs A. A focus group study of primary health care in Johannesburg Health District, South Africa: 'we are just pushing numbers'. S Afr Fam Pr. 2013;56(2):147-52.

51. Strachan DL, Källander K, Ten Asbroek AHA, Kirkwood B, Meek SR, Benton L, et al. Interventions to improve motivation and retention of community health workers delivering integrated community case management (iCCM): stakeholder perceptions and priorities. Am J Trop Med Hyg. 2012;87(5 Suppl):111-9.

52. Frenk J. Reinventing primary health care: the need for systems integration. Lancet. 2009:374(9684):170-3. Elsevier Ltd.

53. Languza N, Lushaba T, Magingxa N, Masuku M, Ngubo T. Community health workers: a brief description of the HST experience. Durban: Health Systems Trust; 2011.

\section{Submit your next manuscript to BioMed Central and we will help you at every step:}

- We accept pre-submission inquiries

- Our selector tool helps you to find the most relevant journal

- We provide round the clock customer support

- Convenient online submission

- Thorough peer review

- Inclusion in PubMed and all major indexing services

- Maximum visibility for your research

Submit your manuscript at www.biomedcentral.com/submit

) Biomed Central 